\title{
Why Not a Nation-Wide Building Code?
}

Research Work of the Bureau of Standards with a View to Learning the Truth About Building Construction

By Geo. H. Dacy

R ECENT house famines, $\boldsymbol{C}$ housing c ongestion, building inadequacies and construction inefficiencies have rung up a reverse English bull's-eye to the extent th a t Government officials and authorized $F$ eder als agencies are now devoting serious study and thought to the matter of systematizing our $h$ a $p h$ a $z$ a $r$ d, catch-ascatch-can methods, modes and measures of construction. In particular, Secretary of Commerce Herbert Hoover has interested himself in the satisfactory solution of our national building enigma. His efforts have resulted in the organization of a special committee of national authorities from the leading building trades and associated industries who, at this writing, are engaged in the formation and perfection of standardized b u i l d i n codes, plumbing codes, hardware codes and the like. In this work of uniformly standardizing the various building trades activities, the national Bureau of Standards is cooperating and doing the majority of the testing and theoretical - as well as much of the inter-

pretative and fundamental-

on building methods.

Right now the Standards experts are comparing the requirements in building codes of some 300 cities in order-as far as is possible and practical-to standardize and unify these construction commandments and to formulate reasonable rules and regulations which will be the basis for potential and safe construction. There are approximately 450 cities in the country at present whose populations range from 10,000 to 25,000 , that are not governed so far as building activities are concerned by standardized requirements. At least 65 per cent of these cities have no building codes whatsoever, while the minor municipalities which boast any codes at all in some cases offer a sort of crazyquilt-like, heterogeneous as sortment of unrelated codes which dovetail together in about the same way that a square is related to a circle. Out of more than 300 American cities with populations in excess of 25,000 onequarter have no building codes while the construction requirements e $\mathrm{n}$ f o r c e d by many of the cities which have codes are variable without any apparent cause. The common plan followed in cities without orthodox building codes has been to use the State building codes, the fire underwriters' codes, or the decisions and judgments of special committees of municipal authorities.

The Federal Government has no power in the matter of these building regulations otherwise than in an advisory capacity, as this work rests entirely with the different states and municipalities. The proposed stand.

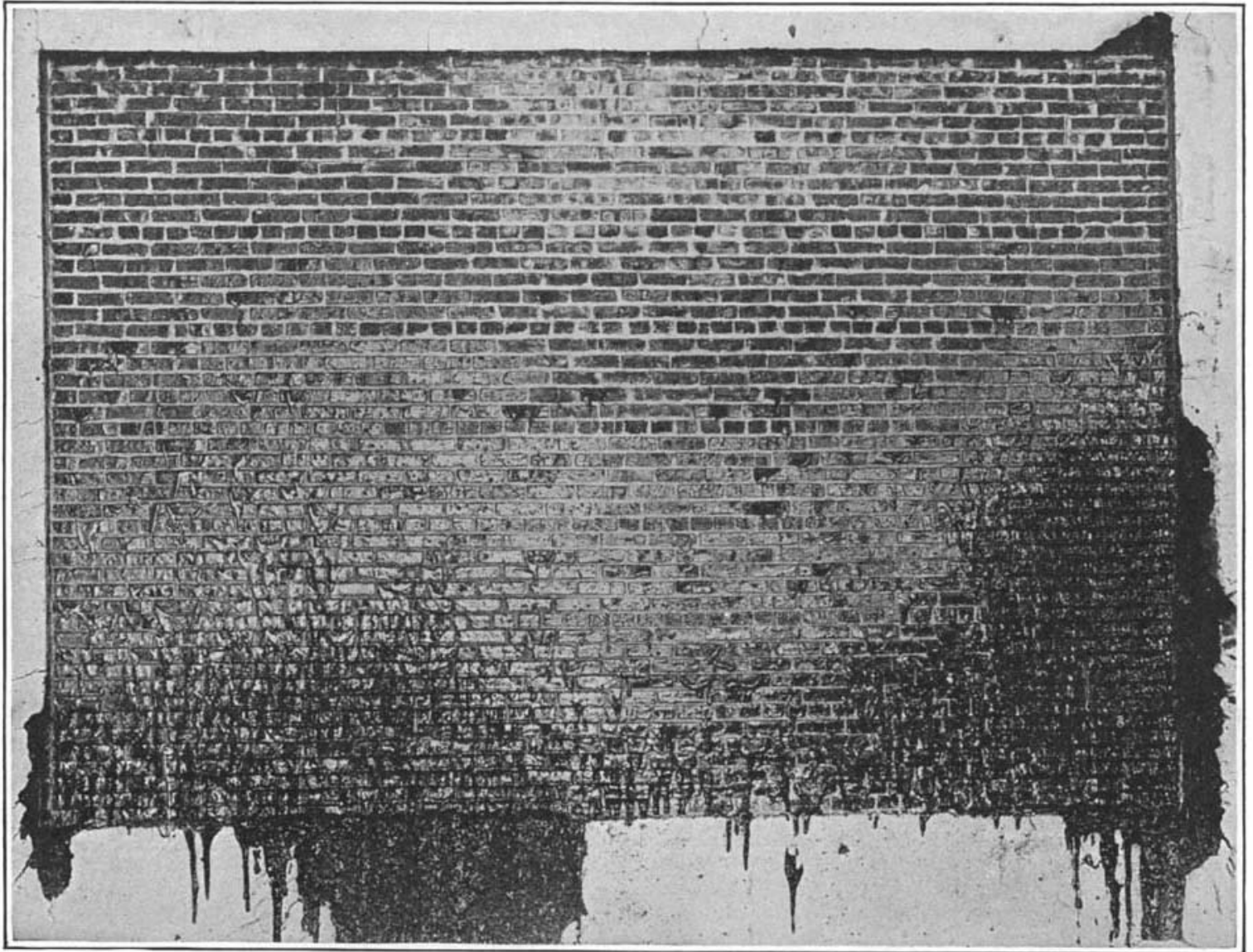

Brick wall, showing the fusion of the soft grades of brick at 2150 degrees Fahrenheit

unique and original tests and investigations. The results emanating from these experimental investigations are of basic importance in emphasizing many of the most significant factors in building codes which, heretofore, have either been ignored through ignorance or have been neglected through carelessness.

Practical, fundamental and essential tests are being made to ascertain the fre resistance of various types of wall construction. In one of the Government testing laboratories, large rolling steel frames have been constructed and are placed in succession directly above a series of powerful oil burners. Brick wall panels of different types 16 feet long, 11 feet high and 8 to 12 inches or more in thickness are built in or close to this steel frame forming one side of the furnace chamber and, subsequently, exposed to flame action at high temperatures for long periods to determine their reactions to cont in ued fire exposure. Generally, these test panels are fred continuously for about 6 hours or until they fail, or show excessive de-

ardization of construction requirements would be of outstanding assistance to the smaller cities which cannot afford the heavy expense of formulating definite local building regulations. Furthermore, such standardization would undoubtedly result in a marked curtailment in building costs and equipment installation expenses in many cases. The Bureau of Standards in reducing the matter of building code systematization to a workaday basis is conducting many worthwhile,

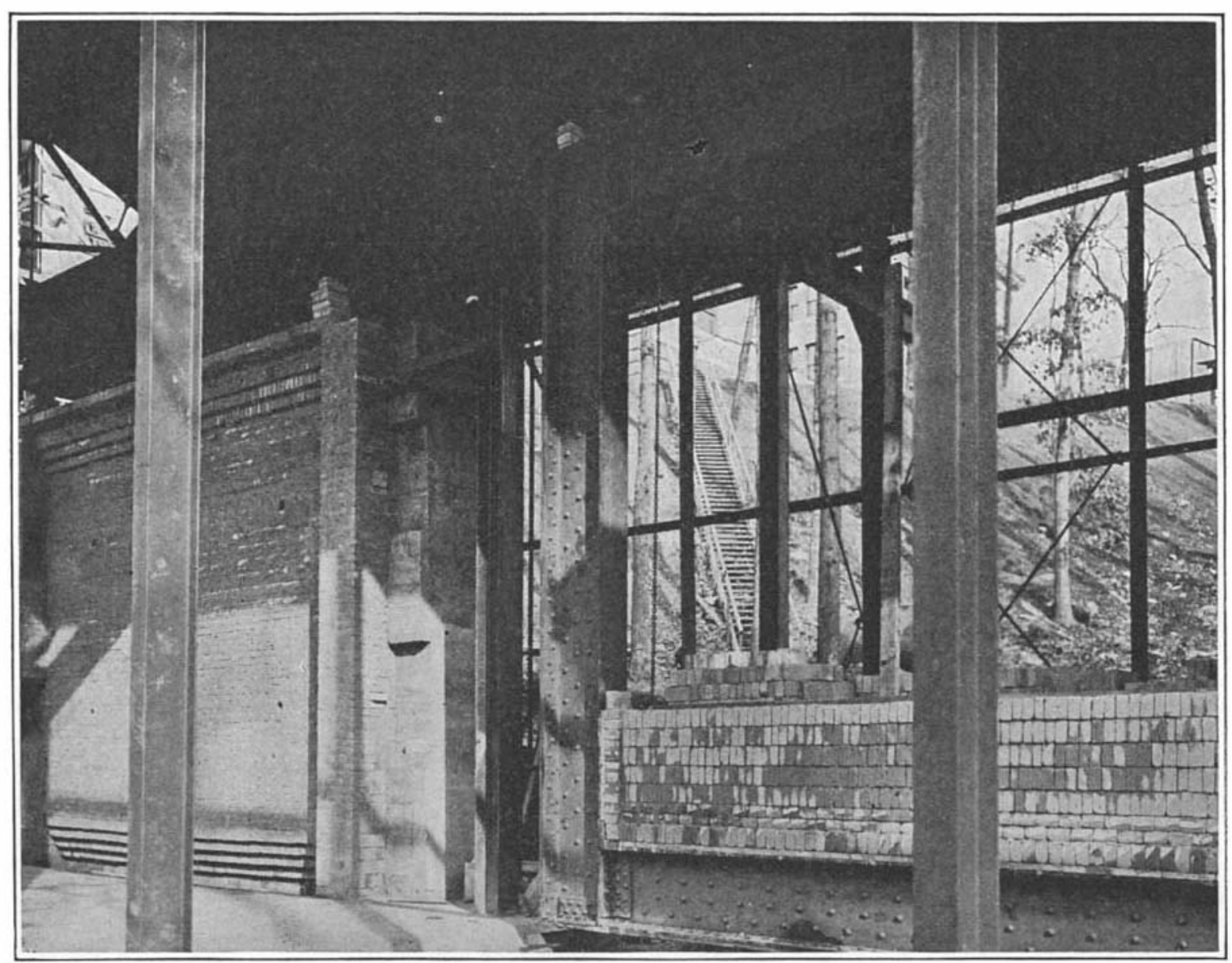

The steel frame used at the Bureau of Standards for the retention of the brick panels subjected to the fire resistance tests terioration and injury. The heat generated by the oil burners is such that at the end of 1 hour, the temperature of the furnace is raised to 1700 degrees Fahrenheit, while it rises to 2000 degrees Fahr. at the termination of 4 hours and attains the peak point of 2150 degrees Fahr. at the end of 6 hours. At this latter temperature, the less resistant varieties of brick melt on the inner face and pour down over the impaired melt on the inner face and pour down over

The Government scientists and engineers in charge of these experiments measure the bulging and inclination of the panel walls towards the flames in order to determine under what conditions the fire is liable to cause the collapse of the brick walls. Various electrical indicating devices are used to measure the temperatures at different portions of the walls during the tests, more than 1000 such temperature readings being taken in the case of each wall panel that is fired. To date, the tests have included the tryouts of both solid and hollow brick walls of 8-inch and 12-inch thicknesses. The steel frame in which the brick panel is built and the panel itself when ready for test weigh about 25 tons and constitute the most ingenious method ever devised for exposing brick walls to fire hazards for experimental purposes.

In the solid wall panels 8 inches thick, 2200 bricks are used, while in the construction of the 12-inch test panels 3300 bricks are required. Where hollow brick walls are used, approximately 25 per cent less brick is used while the labor expenses in building the wall 
are slightly lower than for solid brick, so it is reported.

In general, the purpose of the laboratory fire test with these brick walls is to determine the stability of the different walls; if they will buckle decidedly wher exposed to extremes of heat and flame; and whethe or not they will conduct heat to the extent that articles and goods stored on the opposite side of the wall will also be fired or damaged by the abnormal developmen of heat. The experimental panels are tested under two different conditions: (1) With the walls under ful restraint and built solidly in the steel panel, duplicating conditions that obtain in the lower floors of a tal building, and (2) with open spaces left around the top and sides of the walls to allow them to expand. Thi latter arrangement approximates the conditions which occur in light buildings and on the top floors of many buildings.

During the last 18 months, the Bureau of Standards has been assisting the National Lime Association, the National $A$ ssociation of Plasterers and the American Plasterers' Union to compile a standard plasterin code of countrywide application. This work is now about half completed and promises potentially to modify radically existent deficiencies in plastering operations. Usually the average home owner becomes more familiar with the plastering and plumbing in his house than any other duo of the construction features. Uncle Sam's construction authorities and other national agencies are trying to standardize in black and white the facts and figures which will provide the householder with accurate information which will tell him whether or not his special job of plastering is goodand if it is bad, why it is unsatisfactory. The Burea of Standards has been conducting new and original tests and research activities with lime and gypsum to ascertain inside knowledge about these materials, which, previously, has been unknown. Plasters are made entirely of lime and gypsum which ordinarily have to be used together. In most localities this mean that one or the other of these materials has to be imported at considerable trouble and extra expense. Lime is used because of its plasticity, while gypsum is essential on account of its quick setting characteristics. Heretofore, the individual properties of these tw materials gave no evidences of interchangeability. However, the Government experts have already devised a system which gives plasticity to gypsum and a quick set to lime. These invaluable experiments will result in the future use of one or the other of these materials according to available local resources, but will not re quire the use of both materials to insure durable and satisfactory plaster surfaces. This means a big annual saving to contractors, builders and private individuals and is the sort of worthwhile investigation which merts our hearty commendation.

The Bureau of Standards has also evolved a method of coloring plaster so that attractive and ornamental wall finishes result, which eliminate the necessity for using decorative wall paper.

Little is known about plastering sands by either the laity or building experts. The Government scientist are now conducting a detailed investigation of plastering sands in order to substitute definite facts and figures for our existent ignorance concerning the best types of this building material. They are also devoting Iarticular attention to the perfection of a method of maliing gypsum weatherproof so that it may be use as a finishing material on the exterior of buildings. Their elforts have been effective in a reduction of 50 per cent in the time devoted to the curing of sand-lime bricks and this has meant a great saving in production costs to the manufacturers of this material.

At present, a special new laboratory is being equipped at the Bureau of Standards for investigating the effect of tire on different structural building materials. These tests show that timber weakens about 50 per cent in total strength when exposed to a fire temperature of 100 degrees Centigrade. At exposures of 100 to 150 degrees C., the timbers begin to give off light volatile materials, while at temperatures of 200 degrees C. they become soft and spongy.

Structural grades of steel begin to lose strength when the heat register hovers between the 350 and 400 degree Centigrade mark, while at exposures of from 550 to 600 degrees C. steel fails under average working loads. If the temperature is increased to 800 degrees $C$. the very finest steel possesses only a small fraction of its original strength. The novel apparatus consists of a restraining frame of structural steel, a special loading mechanism and electric furnaces for supplying heat and maintaining the temperature uniform throughout the test specimen. Special temperature recording devices equipped with microscopic facilities for the efficient detection and interpretation of minutely sensitive fluctuations are used in this work. The importance of these fire tests is strikingly indicated when one stops to consider that destructive conflagrations annually cause property losses which aggregate over $\$ 300,000,000$ an amount equivalent to one-fourth the total operatin expenses of the United States Government, and which exceeds the annual appropriations of the United States Army and Navy.

An electric ice machine capable of making one ton of ice daily is being used by the Federal engineers to chill an experimental chamber wherein all kinds of building materials are exposed to weathering condition -laboratory duplications of the deteriorations and damages which obtain from the alternate freezes and thaws and the disruptive operations of Jack Frost. In a single day's exposure in the cold chamber, a sample of building material such as sandstone, marble, granite, concrete or the like is subjected to the same number of climatic vicissitudes as it would undergo in one year's weathering. The rock samples are first soaked in water

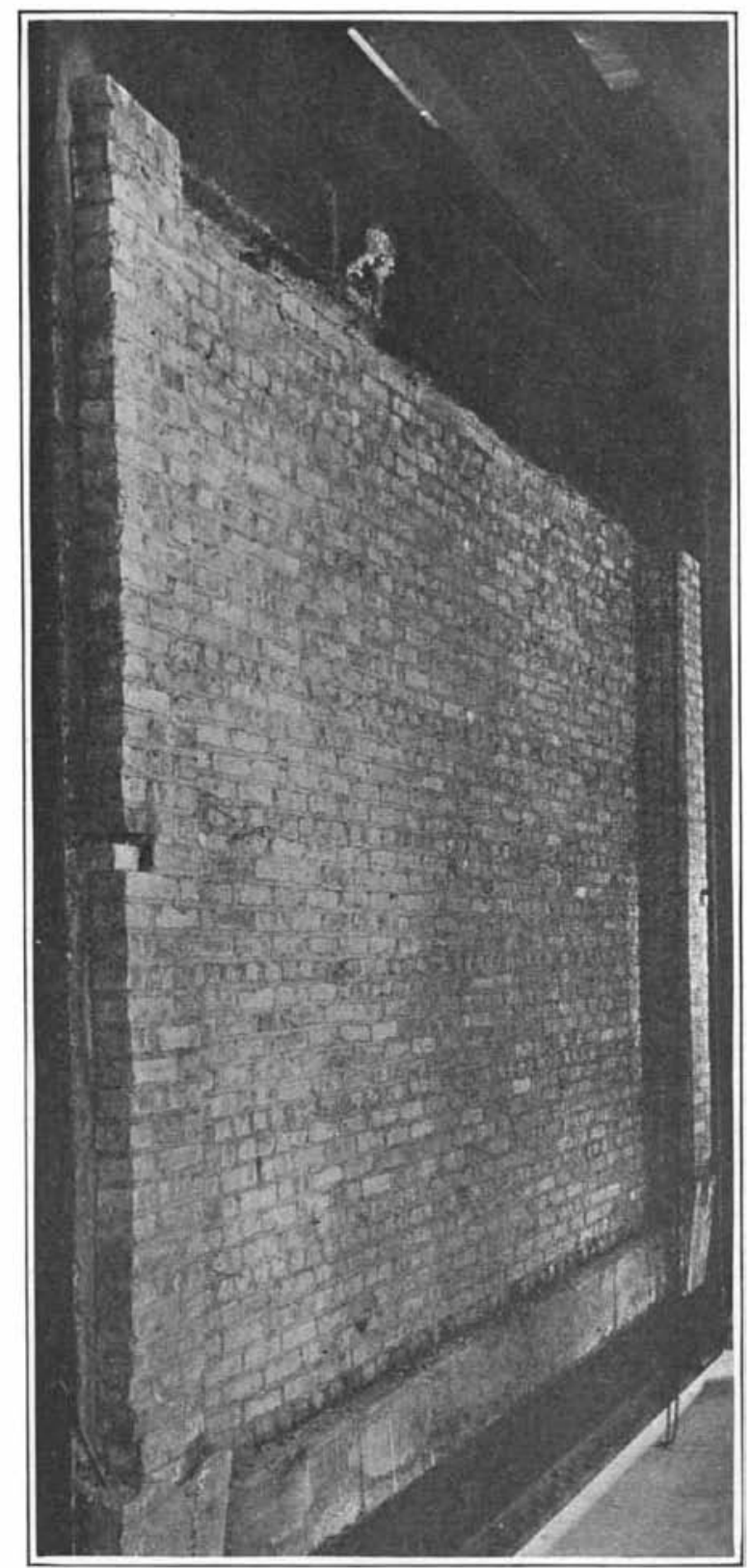

Solid brick wall tested free in the panel. The top of this wall bulged out 6 inches from the top
the pilaster, but sprang back after cooling

and then placed in the novel ice box and subjected to severe and extended freezing. Some of the samples are frozen and thawed 50 to 60 times which is repre sentative of the deterioration they suffer under natural conditions in as many years.

Tests have been made of sandstone similar to that used in the construction of the White House and the National Capitol building. When exposed to alternate freezing and thawing equal to 55 years of weathering, this material broke down and showed marked signs of crumbling. At the time when these Government buildings were erected, this particular variety of Virginia sandstone was popular and largely used for building purposes. The only reason why the executive mansion and the official headquarters for our national lawmakers have lasted so long is because both buildings are protected efficiently and well against weathering injury by regular applications of waterproof paint, which prevents the moisture from penetrating into the stone.
Complete tests of every conceivable mixture and combination of concrete are also under headway as an important phase of the national housebuilding problem. The unique flow table designed and perfected at the Bureau of Standards some time ago for determining the consistency of concrete, is being used to good advantage in these studies. Waterproofing and oil proofing tests of concrete cylinders are being conducted, records being kept of the penetration of cottonseed oils, fuel oils and gasoline into various mixtures of concrete. Nove compression or crushing tests to ascertain the durability of marble, slate, granite and other rock material for building uses are also in progress.

The properties of hollow building tile are being closely studied, this investigation having been in operation for about 12 months. Fire tests are being run of various kinds of tile emanating from different sections of the country.

Extensive experiments have also been carried on to determine the most efficient and satisfactory methods of soundproofing the walls, ceilings and floors of apartment and office buildings. The early investigations have been so successful that work will soon be begun on the construction of a new, large and complete acoustics and sound laboratory where more varied and extensive tests will be run in the future.

The proper, durable and efficient utilization of paint as a preservative and protector of wood has been studied in detail and results of interest and value to the average laymen have been obtained. One common cause of the failure of paint is due to its application in unseasonable weather or due to the fact that it is applied on wet surfaces. The wood surface to be painted should be wholly dry and the weather should be dry and clear when the paint is applied. In order for complete and proper adherence to the wood, the paint must be evenly coated over a moisture-free wooden surface. In itself, the thin layer of paint which is between .001 and .003 inches in thickness, affords but little protection and adds practically no strength to the surface where it is applied unless this work is consummated under the most desirable conditions Light is one of the most destructive agencies which causes paint to deteriorate rapidly. This explains why the dark-colored paints are more durable and weatherworthy than the lighter hues and colors, as the former materials are more opaque and cut off the light more efficiently to the extent that the light has less chance to penetrate to the oil which is the part of the paint which is most susceptible to early injury and decay. One of the greatest economies in house and building decoration would obtain if the public could be educated against the use of white paint for exterior use. Just to show the damaging effect of light on paint, observe the north and south sides of a house that has been painted for some time. Invariably, the paint will fai on the south side of the house before it begins to deteriorate seriously on the northern exposure, due to the larger amount of sunshine and light which concentrate their attack on the south side of the building.

Uncle Sam's specialists are also conducting the most thorough series of experiments relating to the corrosion which occurs in building materials, that have ever been attempted. Metal sheets of various materials used largely in construction work have been exposed to weathering conditions for periods of five years at three different stations in the country, which differ materially in climate.

The Bureau of Standards has also carried on com plete tests of all varieties of stucco. During recent years more than 300 different panels of stucco have been constructed and tested out under actual building exposure conditions. The panels-each of which was 15 feet long and 10 feet high-have been plastered with different combinations of cement, lime and gypsum, the common plastering materials. These panels were erected as part of the exterior walls of a storage building at the Bureau and have been under constant study and scrutiny since their completion. Important facts such as the following resulted from these tests: (1) Cracks which have occurred have not been due to settlement but to an improper method of sheathing (2) Where hair was omitted from the first coat of plaster the lath is more completely imbedded, (3) The lighter shades of stucco show cracks less prominently after wetting than the darker shades, (4) The best method of finishing stuccos is to produce a roug surface such as the "rough-cast" or "pebble-dash" finishes, (5) Stuccos may be satisfactorily applied on monolithic concrete bases and (6) No fundamental cracks have been identified over joints in tile, brick concrete block or gypsum block.

The Bureau of Standards has also run a thorough test of more than 180 structural steel columns used in construction work. 